presence of serum. It was concluded that the power of recognition of the foreign material lay not in the cells but in the serum.

Dr. V. J. McGovern (Sydney) reported on work carried out in collaboration with Dr. D. Bloomfield. The ability of leucocytes to stick to vascular endothelium was investigated using en face preparations. Saline was injected into the adventitia of arteries, and 1.5-3 h later leucocytes stuck to the uninjured endothelial surface. These penetrated the endothelium and continued to do so until about $18 \mathrm{~h}$ after the original trauma. If in making the injection the endothelium was injured to the point of thrombosis, or nearly so, leucocytes stuck to the endothelium much more rapidly. The worse the injury, the sooner did they stick.

The structure of macrophages was the subject of an account by Dr. I. Carr (Sydney). The common feature in granulomata induced by introduction of foreign materials was the presence of spherical masses of phagocytic cells arranged around the foreign material. It was suggested that lipid was phagocytosed in these circum stances by a process which involved the membrane disappearing and the materia] passing into the cell free of membrane. The hypothesis was put forward that the cell membrane may dissolve in the extracellular lipid. The giant cells in these lesions probably are formed largely by cell fusion.

The last paper was that of Dr. E. G. Cleary (Sydney). Dr. Cleary described his analysis of the content of collagen and elastin in samples of human arterial intima and media. More elastin was present proximally and more collagen distally, but the sum of these was constant. The elastin content was probably increased in the new-born; collagen decreased with age. Even muscular arteries were found to contain as much as 52 per cent collagen by chemical analysis.

In his summing up, Sir Roy Cameron commented on the wide range of interest of the symposium, which indicated the emergence of a distinctive Australian approach to experimental pathology. I. CARR

\title{
GELATINE AND GLUE RESEARCH
}

\begin{abstract}
THE twenty-fourth research panel meeting of the British Gelatine and Glue Research Association was held at the Strand Palace Hotel, London, W.C.2, on November 7. The chairman of the Association, Mr. S. G. Hudson (Richard Hodgson and Sons, Bevérley), presided and directed attention to the place of the first paper on wool structure in the research panel series, which has lately included papers on other complex proteins such as collagen ${ }^{1}$ and elastin ${ }^{2}$.

Dr. A. Robson (Wool Industries Research Association, 'Torridon', Leeds) contributed a paper on 'The Sulphur Balance in Wool". In the past it has often been noted that total sulphur analyses for wool are significantly larger than the sum of the individual sulphur-containing compounds estimated by other methods. Most of the sulphur in wool is in cystine, and colorimetric and chromatographic assays of cystine in wool hydrolysates differ by 10 per cent. This fact caused the problem of the sulphur balance to be re-examined. Hydrolysates of wool labelled with sulphur-35 were chromatographed and found to contain several unidentified sulphur compounds, of which one became very abundant when hydrolysis was prolonged. It was identified as bis ( $\beta$-amino- $\beta$-carboxyethyl) trisulphide, that is, the trisulphide analogue of cystine $^{3}$. Thus some of the cystine decomposes during wool hydrolysis and from careful analyses it is concluded that wool contains sulphur only in the form of cystine, cysteine and methionine, thus bringing it into line with other proteins and removing the discrepancy in the sulphur balance. The discussion centred around the mechanism by which the trisulphide artefact might be formed.
\end{abstract}

In the second paper, Mr. L. J. H. Slack (English Abrasives Corporation, Ltd., Tottenham, London, N.17) discussed "Comparisons of Natural and Synthetic Glues in the Coated Abrasives Industry". The industry is a key one in relation to many others of much greater size, for example, metal working. There is a considerable variety of coated abrasives and the glues used include hide glue and synthetics based on alkyds, urea, melamine and phenols. The merits and demerits of hide glue were discussed, and it was concluded that there was need for improvement of the final film properties to enable the natural material to maintain its competitive position.

The director of research, Dr. D. A. Sutton, reported on "Some Recent Impressions of the American Gelatine and Glue Industry". "Emphasis was laid on the speed and hygienic control which are characteristic of the production of American pigskin gelatine; these factors are reflected in the quality of the final product. The plants and processes used were briefly outlined and the other types of gelatine produced were commented on. Attention was directed to the extent to which hide and bone glue production are mechanized in the United States and this factor enables natural glue to be sold at a low price in spite of very high labour rates. There is no central research organization parallel to the British Gelatine and Glue Research Association, but many large companies have large well-equipped laboratories covering all their products and including facilities for gelatine and glue.

$$
\text { D. A. Sutton }
$$

${ }^{1}$ Sutton, D. A., Nature, 196, 223 (1962).

2 Sutton, D. A., Nature, 196, 422 (1962).

${ }^{3}$ Fletcher, J. C., and Robson, A., Nature, 195, 1308 (1962).

\section{THE BRITISH LEATHER MANUFACTURERS' RESEARCH ASSOCIATION}

\begin{abstract}
$A^{N}$ $\mathrm{N}$ outstanding feature of the past year was the strengthening of contacts between the British Leather Manufacturers' Research Association and the footwear industry. The great value of these contacts lies in showing the Research Association how it can adjust its research programme to help the leather industry to meet the requirements of its main customer and they ensure that the Association's work is relevant to the present needs of the footwear industry. The demands made on leather arising from the heat and steam lasting
\end{abstract}

of shoe uppers, for example, are being met and these new methods, which have great advantages, have been established and are likely to increase. A great deal of work has been done on the assessment of different leathers and finishes for these new treatments.

Investigations of skin proteins have continued at the Association's research laboratories, Milton Park, Egham, Surrey, but new emphasis is being given to seasonal variations in lambskins. The methods developed in this long-continued study of the constituents of skin have also 
been applied to the examination of deteriorated leathers under a research project sponsored by the U.S. Department of Agriculture. New work has been the application to collagen and certain tanned collagens of principles and techniques developed by workers in investigations of rubber-like elasticity and the cross-linking of large molecules. Determinations have been made of the number of cross-links (per unit weight) and the relative stabilities of cross-links in collagen tendons tanned with certain aldehydes. It is gratifying to record this beginning of an experimental study of a fundamental question in the theory of tanning and note that glutaraldehyde, first advocated as a tanning agent by the Department of Agriculture, Eastern Regional Laboratory, has been found very effective in producing stable cross-links. Work on curing, enzyme de-woolling and pigment finishing continues.

For many years the Research Association has given forewarnings of the problems facing the industry from effluent disposal. Recent legislation has justified these warnings to the full. Throughout Great Britain, members are steadily adopting the Association's advice to "reduce, replace and re-use". Conditions vary from tannery to tannery so that no one method is likely to be generally applicable, but amounts of lime and sulphide can sometimes be reduced without loss in quality, a proportion of the sodium sulphide normally used can be replaced by caustic soda, and the re-use of lime and chrome is practised on a wider scale. The acute problem of destroying sulphide in effluent has been tackled on a broad front and the costs of various processes for the removal of sulphide have been compared. In addition, the work of the British Leather Manufacturers' Research Association on the behaviour of tannery effluents in biological treatments is proving of immense help in negotiations with local authorities.

Income for the year 1961-62 was $£ 88,698$, an increase of $£ 9,400$ over the previous year; expenditure was $£ 88,816$.

\title{
POLARIZATION OF RADIO SOURCES AND FARADAY ROTATION EFFECTS IN THE GALAXY
}

\author{
By F. F. GARDNER and J. B. WHITEOAK \\ C.S.I.R.O. Division of Radiophysics, University Grounds, Sydney
}

\begin{abstract}
T $\mathrm{N}$ two previous communications ${ }^{1,2}$ observations of linear 1 polarization in the radio emission from a number of extra-galactic sources were reported. The first, by us, gave details of the detection of linear polarization of the radio emission from seven out of nine sources observed at $20 \mathrm{~cm}$. The result is strong support for the hypothesis that the emission originates in synchrotron radiation. A number of these sources were known to be doubles, and in several cases the $E$-vector of the 20 -cm radiation was aligned with the direction of elongation of the source. However, it was pointed out that, owing to the possibility of Faraday rotation, the position angle of the $E$-vector at a single wave-length cannot be used to infer the intrinsic polarization of the source, which on the synchrotron hypothesis ${ }^{3}$ is approximately perpendicular to the magnetic field.
\end{abstract}

The second note, by Cooper and Price ${ }^{2}$, was directly concerned with Faraday rotation. It was found that for three selected points in the radio souree Centaurus $A$ the received polarization progressively rotated with increasing wave-length at a rate proportional to the wave-length squared. This is in agreement with Faraday rotation, for which the rotation $\theta$ in radians at a wave-length $\lambda$ metres by a medium of electron density $N$ per $\mathrm{cm}^{3}$ and longitudinal magnetic field $B_{L}$ in gauss is given by :

$$
\theta=8.1 \times 10^{5} \lambda^{2} \int N B L \mathrm{~d} L
$$

where $L$ is measured in parsecs. We shall call the value of $\theta / \lambda^{2}$ in radians $/ \mathrm{m}^{2}$ the rotation measure for the source. It measures the integrated value of the product of electron density and longitudinal field along the path from the

Table 1. (a) Polarization Directions bor Sources measured at Thrge or More Wave-lengths between 10 and 30 cm

\begin{tabular}{|c|c|c|c|c|c|c|c|c|c|c|}
\hline \multirow[b]{2}{*}{ Source } & \multicolumn{2}{|c|}{$\begin{array}{l}\text { Galactic } \\
\text { Co-ords. }\end{array}$} & \multicolumn{6}{|c|}{ Position angle of polarization (wave-length $\mathrm{cm}$ ) } & \multirow{2}{*}{$\begin{array}{l}\text { Intrinsic } \\
\text { polarization } \\
\text { angle }\end{array}$} & \multirow{2}{*}{$\begin{array}{l}\text { Rotation } \\
\text { measure } \\
\text { radians } / \mathrm{m}^{2}\end{array}$} \\
\hline & lin & $b^{\mathrm{iI}}$ & 30 & 24 & 21 & 19 & 15 & 10 & & \\
\hline $3 C-33$ & 130 & -49 & $33 \pm 5$ & & $60 \pm 2$ & & $81 \pm 5$ & $55-134$ & 94 & -12 \\
\hline Fornax $A(a)^{*}$ & 240 & -57 & $52 \pm 3$ & $64 \pm 3$ & $61 \pm 3$ & $68 \pm 5$ & $67 \pm 3$ & $56 \pm 4$ & 66 & $-1 \cdot 9$ \\
\hline $\begin{array}{l}\text { Fornax } A(b) \\
\text { Pictor } A\end{array}$ & 251 & & $\begin{array}{r}94 \pm 3 \\
169 \pm 3\end{array}$ & $91 \pm 5$ & $\begin{array}{r}101 \pm 3 \\
50+5\end{array}$ & $105 \pm 5$ & $\begin{array}{r}98+5 \\
172+5\end{array}$ & $98 \pm 10$ & 103 & $\begin{array}{l}-1 \cdot 2 \\
+45\end{array}$ \\
\hline Taurus & 185 & -06 & $10 \pm 4$ & & $91 \pm 3$ & & $120 \pm 3$ & $143 \pm 2$ & 157 & $\begin{array}{l}+49 \\
-27\end{array}$ \\
\hline $3 C-161$ & 215 & -08 & $70 \pm 5$ & & $26 \pm 5$ & & & $149 \pm 3$ & 142 & +23 \\
\hline $3 C-270$ & 282 & +67 & $131 \pm 4$ & & $118 \pm 3$ & $118 \pm 10$ & & $108 \pm 8$ & 105 & $+3 \cdot 7$ \\
\hline $3 C-273$ & 290 & +64 & & & $142 \pm 10$ & 20 & $157 \pm 9$ & $156 \pm 3$ & 164 & $-8 \cdot 2$ \\
\hline Centaurus $A(a) \dagger$ & $\mathbf{3 1 0}$ & +20 & $180 \pm 5$ & $138 \pm 4$ & $175 \pm 3$ & $20 \pm 10$ & $70 \pm 3$ & $115 \pm 3$ & 147 & -60 \\
\hline Hercules $\boldsymbol{A}$ & 23 & $\begin{array}{l}+29 \\
+29\end{array}$ & $173 \pm 15$ & & $60 \pm 4$ & & & $25 \pm 4$ & 04 & +24 \\
\hline $3 C-327 a$ & 12 & +38 & $40 \pm 9$ & & $02 \pm 5$ & & & $165 \pm 10$ & 156 & +11 \\
\hline $3 C-353$ & 21 & +19 & $123 \pm 12$ & $24 \pm 4$ & $171 \pm 5$ & $160 \pm 4$ & $137 \pm 3$ & $105 \pm 2$ & 80 & +39 \\
\hline-64 & 321 & -41 & $02 \pm 5$ & & $108 \pm 5$ & & & & 9 & +30 \\
\hline-64 & 314 & -55 & $128 \pm 3$ & & $67 \pm 3$ & $49 \pm 8$ & $47 \pm 9$ & $19 \pm 13$ & 11 & +23 \\
\hline
\end{tabular}

* Fornax $A(a)$ is the larger component at $03 \mathrm{~h} 20 \cdot 5,-37^{\circ} 18^{\prime} ;(b)$ is the smaller one at $03 \mathrm{~h} 22 \cdot 7,-37^{\circ} 28^{\prime}$. At 50 and $75 \mathrm{~cm}$ both components are in the aerial beam.

$\dagger$ Centaurus $A(a)$ is the central component at $13 \mathrm{~h} 23 \cdot 2,-42^{\circ} 48^{\prime} ;(b)$ is in the extended region at $13 \mathrm{~h} 24 \cdot 0,-42^{\circ} 30^{\prime}$.

Table 1. (b) Measurements Not INCluded in Table $1(a)$

\begin{tabular}{|c|c|c|c|c|c|c|c|c|c|c|}
\hline & \multicolumn{2}{|c|}{$\lambda=75 \mathrm{~cm}$} & \multicolumn{2}{|c|}{$\lambda=50 \mathrm{~cm}$} & \multicolumn{2}{|c|}{$\lambda=30 \mathrm{~cm}$} & \multicolumn{2}{|c|}{$\lambda=21 \mathrm{~cm}$} & $\begin{array}{c}\text { Intrinsic } \\
\text { polarization } \\
\text { angle }\end{array}$ & $\begin{array}{c}\text { Rotation } \\
\text { measure } \\
\text { radians } / m^{8}\end{array}$ \\
\hline $\begin{array}{l}\text { Fornax } A(a) \\
3 C=78 \\
3 C=98 \\
3 C=227 \\
3 C-279\end{array}$ & $\underset{0 \pm 10}{P . A .}$ & $2 \cdot 0 \stackrel{\%}{ \pm} 1 \cdot 0$ & $\begin{array}{r}\text { P.A. } \\
25 \pm 5\end{array}$ & $3.5 \stackrel{\%}{ \pm} 1.0$ & $\begin{array}{c}\text { P.A. } \\
135 \pm 10 \\
82 \pm 5 \\
124 \pm 5 \\
0 \pm 5\end{array}$ & $\begin{array}{c}\% \\
3 \cdot 1 \pm 1 \cdot 5 \\
3 \cdot 5 \pm 0 \cdot 5 \\
9 \cdot 3 \pm 3 \\
8 \cdot 4 \pm 1\end{array}$ & $\begin{array}{c}\text { P.A. } \\
124 \pm 7 \\
74 \pm 4 \\
136 \pm 7 \\
153 \pm 3\end{array}$ & $\begin{array}{c}\% \\
2 \cdot 6 \pm 1 \\
6 \cdot 0 \pm 0 \cdot 5 \\
5 \cdot 6 \pm 0 \cdot 5 \\
4 \cdot 3 \pm 1\end{array}$ & $\begin{array}{l}\text { angle } \\
110 \\
65 \\
148 \\
126\end{array}$ & $\begin{array}{c}\text { radians } / \mathrm{m}^{8} \\
+3 \cdot 7 \\
+3 \cdot 5 \\
+\mathbf{3} \cdot \mathbf{7} \\
+10\end{array}$ \\
\hline
\end{tabular}

